\title{
O CASO HISSĖNE HABRÉ E AS POSSIBILIDADES DE INOVAÇÃO EM MATÉRIA DE CORTES REGIONAIS CRIMINAIS
}

\author{
THE HISSÈNE HABRÉ CASE AND THE INNOVATION POSSIBILITIES REGARDING CRIMINAL \\ REGIONAL COURTS
}

Rodrigo Leite

Rafael Lamera Giesta Cabral2

\begin{abstract}
Resumo: Em 30 de maio de 2016, o ex-ditador do Chade, Hissène Habré, havia sido condenado à prisão perpétua por crimes contra a humanidade por um Tribunal Penal Especial (Câmaras Africanas Extraordinárias - CAE) criado no Senegal. A condenação de Habré exterioriza uma importante reorganização no Sistema Africano de Direitos Humanos, como uma das primeiras iniciativas contra a impunidade de crimes cometidos no território africano, por cidadãos africanos, contra a população africana e julgados por Estados também africanos, mas diferentes territorialmente. Ao ser julgado em outro Estado, e com aplicação da legislação internacional e do Senegal, o caso Habré oferece um ponto de inflexão relevante para a compreensão dos sistemas regionais de direitos humanos, ao mesmo tempo em que introduz alternativas para a efetivação desses direitos. O objetivo nesta pesquisa foi analisar o caso a partir de dois pontos: o primeiro, relacionado à forma como a União Africana tem buscado fortalecer os mecanismos de proteção aos direitos humanos no continente, e segundo, ao abordar a elasticidade interpretativa dada ao caso que, além de julgar casos de violação de direitos humanos realizados em outro Estado (Chade), aplicaram-se também leis próprias (do Senegal) para a persecução da punição. Para que os resultados fossem alcançados, produziram-se uma revisão bibliográfica e uma pesquisa descritiva, a partir do estudo de caso. A criação da CAE pode ser compreendida como uma tentativa de incorporar uma jurisdição penal regional para condenar aqueles que cometem crimes contra a humanidade na África em detrimento do Tribunal Penal Internacional.
\end{abstract}

Palavras-chave: Direitos humanos. Sistema africano. Hissène Habré.

\footnotetext{
1 Mestre em Direito Comunitário (Ciência Jurídico-Comunitária) pela Universidade Clássica de Lisboa, Portugal; doutorando em Ciência Política pela Universidade Federal de Pernambuco; Professor no Curso de Direito da Universidade Federal Rural do Semi-Árido; rodrigoleite@ufersa.edu.br; https://orcid.org/0000-0002-6722-4493

2 Doutor em Direito, Estado e Constituição pela Universidade de Brasília; Mestre em Ciência Política pela Universidade Federal de São Carlos; Professor no Curso de Direito e no Programa de Pós-Graduação (Mestrado Profissional) em Administração Pública da Universidade Federal Rural do Semi-árido; Avenida Francisco Mota, 572, CCSAH, Sala 09, Cidade Universitária, 59625-900, Mossoró, Rio Grande do Norte, Brasil; rafaelcabral@ufersa.edu.br; http://orcid.org/0000-0002-6442-4924
} 


\begin{abstract}
On May 30, 2016, the dictator of Chad, Hissène Habré, had been sentenced to life imprisonment for crimes against humanity by a Special Criminal Court (Extraordinary African Chambers - CAE) created in Senegal. Habré's condemnation means a major reorganization of the African Human Rights System as one of the first initiatives against the impunity of crimes committed on African territory by African citizens against the African population and judged by African states that are territorially different. When judged in another state, and also with application of the international law and Senegal's law, the Habré case provides a relevant inflection point for the understanding of regional human rights systems, while introducing alternatives for the realization of these rights. The objective of the research was to analyze the case from two points: the first, related to the way in which the African Union has sought to strengthen the mechanisms for the protection of human rights in the continent, and secondly, by addressing the interpretative elasticity given to the case that, in addition to prosecute cases of human rights violations carried out in another state (Chad), its own laws (Senegal) were also applied to pursue punishment. In order to achieve the results, the research produced a bibliographic review and a descriptive research, from the case study. The creation of the CAE can be understood as an attempt to incorporate a regional criminal jurisdiction to convict those who commit crimes against humanity in Africa to the detriment of the International Criminal Court.
\end{abstract}

Keywords: Human rights. African system. Hissène Habré.

\title{
Introdução
}

Em 30 de maio de 2016, a União Africana anunciava que o ex-ditador do Chade, Hissène Habré, havia sido condenado à prisão perpétua por crimes contra a humanidade, execução sumária, tortura, rapto e estupro, por um Tribunal Penal Especial criado no Senegal. A condenação do exditador foi recebida pela comunidade internacional de proteção aos direitos humanos como uma decisão histórica contra a impunidade, ao mesmo tempo que reforçava o compromisso africano de proporcionar justiça às vítimas daquela ditadura imposta por Habré.

A história do Chade, país localizado na região Centro-Norte da África, não pode ser resumida de maneira simples, uma vez que pode ser compreendida, no mínimo, a partir de duas tendências distintas. Em 11 de agosto de 1960, o Chade tornou-se independente da exploração colonial francesa e foi inserido na mesma lógica que marcava os países recém-independentes: a prática comum exercida pelas grandes potências em naturalizar apoio econômico e militar à ditadores para aprimorarem vantagens estratégicas, mesmo que fosse ao custo de violações sistemáticas de direitos humanos contra as respectivas populações locais. ${ }^{3}$ Essa primeira tendência se encerra com a falência de tais regimes, muitas vezes, marcada por transições de ditadura para experiências não autoritárias. Nesse aspecto, abre-se espaço para uma tendência inédita, que busca responsabilização pública e judicial àqueles que promoveram a perpetração de violações de direitos humanos. Tradicionalmente, essas demandas são incluídas dentro dos pilares que sustentam a ideia de uma Justiça de Transição.

$\mathrm{O}$ ex-ditador Hissène Habré pode ser compreendido dentro de um período que abrange essas duas tendências. Assumiu o poder no Chade em 1982, com um aglomerado apoio de países e grupos dissidentes, e em pouco mais de oito anos, quando foi deposto, estimou-se que o ex-ditador foi

\footnotetext{
3 Para um aprofundamento, ver: Marks (2004).
} 
responsável por aproximadamente 40 mil homicídios de opositores políticos e membros de minorias étnicas, e por mais de 200 mil casos de torturas e outros crimes contra a humanidade, conforme a Human Rights Watch (2005). Deposto em 1990, exilou-se no Senegal e, sem apoio, acabou sendo preso nesse país, aguardando julgamento por seus crimes.

A União Africana e o Senegal, em 2012, realizaram um acordo para a criação das Câmaras Africanas Extraordinárias (CAE), órgão que seria o responsável pelo julgamento do ditador. Em 30 de maio de 2016 o processo foi concluído com a condenação à prisão perpétua, tendo como base o cometimento de crimes contra a humanidade. $O$ recurso contra essa decisão foi julgado em janeiro de 2017, com manutenção da sentença. O processo ficou conhecido como o caso Hissène Habré.

A condenação do ex-ditador, embora esperada, pode ser compreendida sob múltiplas perspectivas. Não se tratava apenas de uma luta contra a impunidade de crimes cometidos pelo regime ditatorial de Habré. A solução do caso reflete uma importante reorganização no próprio sistema regional de proteção aos direitos humanos do continente africano, como uma das primeiras iniciativas contra a impunidade de crimes cometidos no território africano por cidadãos africanos contra a população africana e julgados por Estados também africanos, mas diferentes territorialmente. ${ }^{4}$

Esse ineditismo no julgamento de Habré trouxe à tona inovações que merecem ser investigadas, e esse é o principal objetivo deste trabalho, demonstrar o impacto dessa decisão regional diante do sistema internacional de proteção aos direitos humanos e como o caso pode ser refletido a partir das interações filosóficas produzidas no âmbito da Justiça de Transição.

\section{Dos fatos. A história processual do caso Hissène Habré na Câmara Africana Extraordinária}

Desde 1990, após ser destituído do poder no Chade, o ex-ditador Habré exilou-se no país vizinho, Senegal. A concessão do asilo político pelo governo senegalês foi objeto de inúmeras controvérsias, principalmente pela condição de ser acusado de cometer crimes internacionais. Ao lado da história de seu exílio, o contexto de impunidade tem como pano de fundo um cenário de iniciativas que buscam a condenação pública de violadores de direitos humanos, principalmente em contextos de transição de regimes ditatoriais para a democracia.

Em junho de 2013, a polícia senegalesa efetivou sua prisão e o manteve à disposição da Câmara Africana Extraordinárias para julgamento de crimes contra a humanidade. No entanto, a história de seu julgamento não tem como ponto de partida sua prisão em $2013 .{ }^{5}$ Em fevereiro de 2000, o juiz senegalês M. Demba Kandji formalizou, a partir das leis senegalesas, a acusação em desfavor de Habré por crimes contra a humanidade, atos de tortura e barbárie. O processo decorria

\footnotetext{
4 Taffo (2015) recorda que o Tribunal Especial de Serra Leoa, em 1996, foi coordenado pela Organização das Nações Unidas e não deixa de ser um exemplo também histórico, mas o que o diferencia do caso Hissène Hebré é o fato de ser uma solução continental, sem controle ou influência de outras organizações internacionais.

5 O resgate histórico do processo de Hissène Habré tem como referência os estudos de Navarro (2013).
} 
de denúncias de vítimas do regime de Habré, bem como reflexo das comissões de investigação realizadas no Chade, que averiguaram inúmeros casos de detenções ilegais, desaparecimentos forçados, torturas e assassinatos em massa praticados no governo do ex-ditador, indicando sua ação direta nas violações em massa de direitos humanos. Poucos meses após a abertura do processo, o Tribunal anulou o procedimento sob a alegação de ausência de jurisdição dos órgãos senegaleses (NAVARRO, 2013).

Com a ausência de uma investigação criminal pelos países africanos, vítimas de Habré, asiladas na Bélgica, solicitaram, ainda em 2005, intervenção do governo belga, e posteriormente da Corte Penal Internacional (em 2009), para que promovessem pedido de extradição do ex-ditador para julgamento na Bélgica. O pedido de extradição foi negado sob a alegação de ausência de competência para a extradição, principalmente pela possível imunidade diplomática concedida ao acusado pela condição de ex-presidente do Chade. Sucessivos pedidos de extradição foram ignorados (CARVAJAL, 2012; NAVARRO, 2013), mesmo diante da decisão da Corte Internacional de Justiça (Corte da Haia) que, em 2012, determinou, com base na Convenção das Nações Unidas contra a Tortura e Outros Tratamentos e Penas Cruéis, Desumanos ou Degradantes (1984), que a República do Senegal tinha obrigação internacional de extraditar Habré para a Bélgica ou de processá-lo em sua jurisdição, conforme a cláusula extraditare vel iudicare.

Por outro lado, o próprio Senegal realizou uma consulta junto à União Africana para solicitar apoio para a tomada de decisão, que resultou em uma determinação significativa da organização africana: "manda a República do Senegal processar e julgar, em nome da África, Hissène Habré, por uma jurisdição senegalês competente para garantir um processo justo." ${ }^{\prime 6}$ A decisão da União Africana se ancorou na Convenção contra a Tortura, da ONU. Navarro também destaca que a União Africana criou um Comitê de Juristas para avaliar o caso e que a postura de seus membros foi coerente com a evolução da doutrina da imunidade de chefes de Estado ao excepcionar a regra em casos de crimes internacionais (NAVARRO, 2013).

No entanto, Habré resistiu a essa decisão contra o Senegal junto à Corte Africana de Direitos Humanos e dos Povos em 2008, e posteriormente, no Tribunal de Justiça da Comunidade Econômica da África Ocidental. O argumento era que o processamento pelo Senegal constituiria a violação ao princípio da retroatividade, com grave violação a um dos pilares da ideia de segurança jurídica. $O$ impasse entre o processamento e a legitimidade dos tribunais se arrastou por um longo período de tempo, mas também não deixava de refletir questões políticas e jurídicas, bem como questões de exercício de soberania.

A solução encontrada foi criar um Tribunal Especial ad hoc, criado única e exclusivamente para promover o julgamento de Hissène Habré pelos crimes cometidos entre 1982 e 1990 . No entanto, não se pode ignorar que a evolução legislativa e processual para o julgamento de Habré pelo

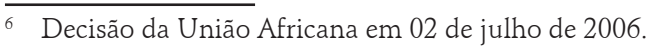


Senegal foi fruto de inúmeras pressões internacionais, de organizações não governamentais e das próprias vítimas do ex-ditador.

Em julho de 2013, iniciou-se a preparação do processo de Habré nas Câmaras Africanas Extraordinárias. Em 13 de fevereiro de 2015, o Comitê apresentou uma denúncia completa contra o ex-ditador que refletia as ações de investigações por mais de 20 anos. $^{7}$ Após os trâmites processuais, em 30 de maio de 2016, o Tribunal o condenou à prisão perpétua por ter cometido crimes contra a humanidade. O recurso contra essa decisão foi julgado em janeiro de 2017, com manutenção da sentença.

A sentença, um documento de 681 páginas em língua francesa, ${ }^{8}$ reflete bem o trabalho desenvolvido pela CAE. Detalha minuciosamente desde a fundamentação jurídica da CAE aos fatos históricos envolvidos, os relatos dos crimes, estabelecendo as relações de causalidade e a dosimetria da pena. Ao final, a CAE considerou Habré culpado de: a) crimes contra humanidade, por estupro, escravidão sexual, assassinato, execução sumária e atos desumanos; b) tortura; c) crimes de guerra, por homicídio, tortura, tratamento desumano, detenção ilegal e tratamento cruel. ${ }^{9}$ Além da aplicação da pena de prisão perpétua, Habré foi condenado a pagar indenizações às vítimas.

Segundo Høgestøl (2016), o julgamento de Habré colocou em destaque o fato de ser a primeira pessoa a ser julgada no âmbito de um mecanismo africano de justiça criminal internacional. Em grande parte, esses esforços por punição refletem as ações das vítimas que levaram à persecução penal do ex-ditador e uma mudança significativa de posicionamento do sistema africano de direitos humanos diante das denúncias de violação em massa de direitos de seus cidadãos praticados por agentes do Estado.

\subsection{0 direito - controvérsia em torno da criação de um tribunal internacional ad hoc}

Em agosto de 2012, Senegal e a União Africana oficializaram um acordo para a criação das Câmaras Africanas Extraordinária (CAE), ratificado pelo parlamento senegalês no mesmo ano. Esse acordo trazia como anexo o Estatuto da CAE, com as regras de seu funcionamento. ${ }^{10}$ As Câmaras foram composta de quatro sessões: uma de instrução, com quatro juízes senegaleses, uma de acusação, com três juízes senegaleses, uma de primeira instância e outra de apelação, cada uma com dois juízes senegaleses e um presidente de outro país, pertencente aos quadros da União Africana e indicados por esta, com aplicação da legislação processual de Senegal.

Sobre as características desse novo tribunal, Høgestøl (2016) explica que as câmaras teriam natureza internacional, ainda que incorporada ao sistema judicial senegalês, aplicando tanto

\footnotetext{
A denúncia do processo pode ser visualizada em: Chambres Africaines Extraordinaries (2015).

8 Sentença disponível no website da CAE (http://www.chambresafricaines.org/). Diretamente em: Chambre Africaine Extraordinaire D'Assises (2016).

9 Cfr. a sentença do caso Habré, p. 527, pár. 2290.

$10 \mathrm{O}$ acordo e o Estatuto da CAE podem ser encontrados em: Chambres Africaines Extraordinaires (2017).
} 
o direito internacional, quanto o código penal de Senegal. Assim, poderia ser classificado como um tribunal "internacionalizado", semelhante ao criado sob a administração da ONU em Timor Leste e no Kosovo. Esse tipo de corte sugere que elementos internacionais são introduzidos no sistema de tribunais domésticos, contrastando com os tribunais internacionais criminais "puros", que foram criados em Ruanda e na ex-Iugoslávia, sendo estes de natureza independente e com a aplicação exclusiva do direito internacional.

A CAE é, então, considerada por Høgestøl (2016) como um tribunal criminal internacionalizado "minimalista", e os principais elementos internacionais encontrados nesse modelo são: a) a aplicação do direito internacional; b) está sendo regulamento por um estatuto especial; c) a inclusão de juízes indicados e nomeados pela União Africana (não todos). A competência do tribunal, de acordo com o art. 4 do estatuto, abrange crimes de guerra, crimes contra a humanidade, genocídio e tortura. Nesse ponto, o estatuto também dá primazia ao direito internacional, porém também confere ao direito nacional senegalês um papel importante no processo, estipulando que, para os casos não previstos no Estatuto, os procedimentos senegaleses e a lei substantiva do país será aplicada.

Um último fator de exclusividade da CAE é sua base universal, em vez de jurisdição territorial. Até então os tribunais criminais internacionalizados eram localizados dentro do território onde os crimes foram cometidos. A jurisdição da CAE, no entanto, é sobre crimes internacionais cometidos no território do Chade durante o período compreendido entre 07 de junho de 1982 e 01 de dezembro de 1990, significando que a CAE não se situa apenas fora do território em que os crimes foram cometidos, mas que também se baseia exclusivamente na jurisdição universal. Essa é a primeira vez que um tribunal foi construído sobre tal base no direito penal internacional. Também vale a pena notar que a jurisdição pessoal da CAE é mais ampla do que apenas a persecução a Habré. O tribunal tem jurisdição sobre todas as pessoas que eram provavelmente responsáveis pelos crimes cometidos no Chade, e assim, pode ser que a estrutura do Tribunal seja ser utilizada no futuro (HØGESTØL, 2016).

\subsection{0 sistema africano de direitos humanos}

A proteção dos direitos humanos no continente africano em alguns aspectos possui conotações distintas do continente europeu e americano. Existem conceitos compatíveis com a defesa da dignidade humana, mas que reconhecem aspectos que para a cultura ocidental pareceriam estranhos, como a prevalência dos direitos coletivos sobre os individuais e a necessidade de vincular a pessoa a sua respectiva comunidade. Assim, o continente africano em sua forma de visualizar os direitos humanos entrecruza conceitos de diferentes perspectivas de natureza ideológica, religiosa e cultural (SOLER, 2012).

Todas essas questões necessitavam de uma organização internacional que gerenciasse essas disparidades. Depois do fracasso da União dos Estados Africanos, criada em 1957, constituiu-se em 1963 a Organização para a Unificação Africana (OUA). Essa foi a primeira organização supranacional 
que abarcava todo o continente. O seu tratado constitutivo ficou conhecido como Carta de Adis Abeba, e incluiu entre os seus objetivos a cooperação internacional em matéria de direitos humanos, tomando como referência os textos aprovados pela ONU (SOLER, 2012). No entanto, a ausência de referências mais diretas e completas sobre o tema dos direitos humanos fez com que essa Carta fosse o pilar mais frágil de todo o sistema de proteção africano de direitos humanos (RKIOUA, 2012).

Assim, a consolidação de um sistema de direitos humanos foi bastante dificultada, pois as prioridades da organização acabaram sendo a descolonização e o desenvolvimento econômico de seus Estados. Adiante, com o impacto da guerra fria, a dependência econômica do exterior e os enfrentamentos regionais, além do impacto de regimes ditatoriais, impediram o avanço da integração da União por três décadas (SOLER, 2012).

Ante esse quadro, surgiu a necessidade de um novo modelo de integração dos países, que foi realizado com a aprovação em 2000 da Ata Constitutiva da União Africana (UA), que dissolveu a OUA e converteu a UA na base organizacional para o sistema regional africano de direitos humanos.

No entanto, no âmbito dos direitos humanos, observa-se que a partir de 1970 se iniciou um movimento tendente à criação de um documento no estilo de uma declaração dos direitos humanos para o povo africano. O resultado foi a aprovação em 27 de julho de 1981 da Carta Africana de Direitos Humanos e dos Povos (Carta de Banjul).

Uma das características mais importantes da Carta de Banjul é o reconhecimento, em um mesmo texto, dos tradicionais direitos civis e políticos, econômicos, sociais e culturais, em conjunto com direitos individuais e coletivos (FREITAS; MACEDO, 2013). Ainda mais inovador, em verdade não há uma distinção de natureza entre esses direitos, atribuindo-lhes força jurídica igual (PIRES, 1999; BICUDO, 2003).

Em caso de conflito, os direitos coletivos podem prevalecer sobre os individuais. No capítulo $2^{\circ}$ da Carta existe também um rol de deveres que todo indivíduo tem para com "sua família e sociedade, para com o Estado e outras comunidades legalmente reconhecidas, assim como para a comunidade internacional." Outro diferencial é a coexistência do acervo internacional com as práticas tradicionais da cultura africana. Explica o texto, em seus arts. 60 e 61, que os princípios aplicáveis pela Comissão Africana de Direitos Humanos respeitarão não apenas a legislação internacional, mas tomarão em consideração medidas subsidiárias como as "práticas africanas", os "costumes geralmente aceitos", "os precedentes legais e as crenças" (SOLER, 2012).

Contudo, a Carta de Banjul também sofreu críticas. Entre elas, indica-se que o reconhecimento dos direitos mostra dispositivos vagos (PIRES, 1999), a existência da primazia dos direitos coletivos sobre os individuais (MUNIÁIN, 1999) e a continuidade de uma visão anticolonial ou antiocidental herdeira dos velhos princípios fundadores da OUA (SOLER, 2012).

No aspecto institucional, a União Africana conta com órgãos como a Comissão Africana dos Direitos Humanos, o Comitê Executivo, um Parlamento Pan-africano e uma Corte Africana dos Direitos Humanos. 
A Comissão Africana foi criada junto com a Carta Africana de Direitos Humanos, ainda na época da OUA, que de acordo com o art. 30 desse documento, foi encarregada de "promover os direitos humanos e dos povos e de assegurar a respectiva proteção na África." Nos termos do art. 31, a Comissão é composta por 11 membros que devem ser escolhidos entre personalidades africanas que gozem da mais alta consideração, conhecidas por sua alta moralidade, sua integridade e sua imparcialidade, e que possuam competência em matéria dos direitos humanos e dos povos, devendo ser reconhecido um interesse particular na participação de pessoas possuidoras de experiência em matéria de direito. Esses membros exercem suas funções a título pessoal.

As funções da Comissão estão estabelecidas no art. 45 da Carta Africana dos Direitos Humanos e incluem uma série de competências, como a publicação e revisão de relatórios, interpretação de normas e organização de conferências. ${ }^{11}$ No entanto, a função mais importante é a realizada por meio dos denominados Comunicados (arts. 47 a 59), que são demandas apresentadas pelos Estados ou por outros sujeitos que não sejam Estados-membros, sendo que de forma excepcional se permite apresentação de comunicados a título individual ou coletivo, que não serão anônimos, ante a constatação da violação das disposições da Carta, permitindo, assim, que a Comissão realize as investigações necessárias.

Sem embargo, existem duas questões que restringem o âmbito de atuação da Comissão: o princípio do esgotamento prévio de todos os recursos legais previstos pelo Estado onde se produz a violação de direitos humanos (art. 50), e o caráter não vinculante, não obrigatório e confidencial de suas resoluções. Nesse passo, somente há a possibilidade de chamar a atenção sobre as circunstâncias do caso e elaborar recomendações para os Estados infratores (art. 53 e 58), sem possibilidade de impor sanções.

A partir dos anos 1990, com o aumento do regime democrático nos países africanos, e observando-se as limitações da Comissão Africana, iniciaram-se as tratativas para implantar uma Corte de Direitos Humanos no regime da UA. Assim, aprovou-se em 1998 o Protocolo Adicional da Carta Africana de Direitos Humanos e dos Povos, sobre o estabelecimento de uma Corte Africana de Direitos Humanos. Esse instrumento constituía a Corte e aprovava seu Estatuto. No entanto, a entrada em vigor do Protocolo somente realizou-se em 21 de janeiro de 2004, e apenas em 2006 realizou-se a sessão constitutiva do Tribunal.

De acordo com o Protocolo Adicional, o tribunal é composto por 11 juízes, cidadãos dos Estados-membros da UA, eleitos pela Conferência dos Chefes de Estado e de Governo da União

\footnotetext{
11 Essas funções são as seguintes: "A Comissão tem por missão: 1.Promover os direitos humanos e dos povos e nomeadamente: a) Reunir documentação, fazer estudos e pesquisas sobre problemas africanos no domínio dos direitos humanos e dos povos, organizar informações, encorajar os organismos nacionais e locais que se ocupam dos direitos humanos e, se necessário, dar pareceres ou fazer recomendações aos governos; b) Formular e elaborar, com vistas a servir de base à adoção de textos legislativos pelos governos africanos, princípios e regras que permitam resolver os problemas jurídicos relativos ao gozo dos direitos humanos e dos povos e das liberdades fundamentais; c) Cooperar com as outras instituições africanas ou internacionais que se dedicam à promoção e à proteção dos direitos humanos e dos povos; 2.Assegurar a proteção dos direitos humanos e dos povos nas condições fixadas pela presente Carta. 3.Interpretar qualquer disposição da presente Carta a pedido de um Estado Parte, de uma instituição da Organização da Unidade Africana ou de uma organização africana reconhecida pela Organização da Unidade Africana. 4.Executar quaisquer outras tarefas que lhe sejam eventualmente confiadas pela Conferência dos Chefes de Estado e de Governo." (Art.45 da Carta Africana de Direitos Humanos).
} 
Africana para um mandato de seis anos, podendo se reeleger por mais um mandato. As reuniões do tribunal acontecem, ao menos, quatro vezes por ano.

A Corte Africana possui ainda competência consultiva e contenciosa. Na primeira, o tribunal poderá emitir pareceres sobre a interpretação dos dispositivos da Carta Africana ou de qualquer outro instrumento de proteção dos direitos humanos. Por sua vez, em sua função contenciosa, cabe à Corte analisar os processos submetidos pela Comissão ou pelos Estados-membros. A aprovação de processos apresentados por indivíduos e ONGs está condicionado ao fato de os Estados dos quais os requerentes sejam nacionais terem declarado, expressamente, que aceitam a submissão de demandas individuais ao Tribunal, no momento da ratificação do documento ou posteriormente, conforme versa o artigo 34 do Protocolo. Ou seja, no sistema africano, opina Piovesan (2014), os indivíduos podem levar demandas diretamente ao Tribunal, mas isso representa uma acessibilidade limitada. Essa foi uma saída "eclética" dos autores do Protocolo, que optaram por não copiar algum modelo já existente (CARVAJAL, 2012).

No âmbito da competência contenciosa, a Corte Africana busca encontrar uma solução amistosa entre o Estado e os peticionários. Em caso de comprovação da existência de violações de direitos humanos, o tribunal profere uma sentença determinando as medidas de reparação necessárias, podendo inclusive emitir medidas provisórias em casos graves e urgentes.

Para supervisionar o cumprimento das sentenças da Corte Africana de Direitos Humanos, foi designado um Conselho de Ministros, órgão de caráter político, inspirado no modelo do sistema europeu de direitos humanos (PIOVESAN, 2014). Mas diferentemente do sistema europeu, o Conselho que supervisiona o cumprimento das sentenças da Corte Africana não possui a faculdade de impor sanções aos Estados. Essa competência é retida pela Assembleia Geral da União Africana, e as sanções são apenas previstas para os casos em que se cometeram crimes de genocídio, crimes de guerra e de lesa-humanidade. Dessa forma, os casos que chegam à Corte Africana não são desse tipo, e assim, a possibilidade de aplicação de sanções por descumprimento das sentenças é limitado. O mais provável que pode acontecer, destaca Álvarez (2008), é uma condenação pública por parte da Assembleia Geral da UA para pressionar os Estados a cumprir as decisões da Corte.

Apesar dos progressos evidentes ao longo dos anos, o sistema africano de proteção ainda é considerado um dos mecanismos regionais mais fracos em comparação com outras experiências continentais. Em comparação com o muito mais consolidado Tribunal Europeu dos Direitos do Homem ou a Corte Interamericana, Polymenopoulou (2012) considera que o sucesso do Tribunal Africano até agora foi limitado. A dificuldade de proporcionar justiça num continente que testemunhou muitas das piores atrocidades, junto com a falta de autoridade do sistema para se fazer cumprir, têm sido fatores relevantes. Este último é igualmente desencadeado por alguns problemas funcionais, como a lentidão dos procedimentos e a impossibilidade de petições individuais na maioria dos Estados signatários do Protocolo, bem como a falta de conhecimento por parte dos indivíduos da existência do Tribunal em muitos casos. 
Além desses fatores, as cláusulas de clawback também dificultam a segurança jurídica do sistema. Essas cláusulas permitem que em circunstâncias normais, obrigações de garantias de direitos sejam desrespeitadas. Frise-se que essas cláusulas não estão sujeitas a controles internacionais ou supranacionais. Pelo contrário, permitem que a legislação nacional tenha prevalência quando dois dispositivos legais (internacional e nacional) de direitos humanos estejam em choque. No caso específico, a previsão dessas cláusulas de clawback não faz menção ao envolvimento da Comissão Africana de Direitos Humanos, e assim, o sistema torna-se fragilizado pela possibilidade e uso constante desse tipo de recurso (KUFUOR, 2010; POLYMENOPOULOU, 2012). ${ }^{12}$

Nos últimos 17 anos, o caso Hissène Habré acaba por ser um ponto fora da curva e tem potencial para alterar, de maneira significativa, a relação da União Africana e seu sistema de proteção regional aos direitos humanos diante das violações em massa de direitos.

Como se pôde observar na seção anterior, o caso Habré extrapolou inúmeras experiências de impunidade. Por mais que seja possível constatar as resistências do Senegal em realizar o julgamento do ex-ditador, a ponto de se prolongarem conflitos jurisdicionais entre os governos belga e senegalês, por processamento ou por extradição, constata-se que tanto Senegal quanto a União Africana exploraram opções inéditas para acionar os mecanismos de justiça regional para proteção dos direitos humanos.

A opção por um Tribunal Especial ad hoc não é uma experiência inédita no contexto do direito internacional. No entanto, guarda em seu bojo um conjunto amplo de complexidade que foge à regra dos sistemas de proteção, principalmente pela capacidade de impor responsabilizações em contexto excepcionais.

Quanto à responsabilização, a diferença das cortes de direitos humanos para o Tribunal Penal Internacional (TPI) (e os demais Tribunais Penais ad hoc existentes), é que nestes, busca-se condenar o agente estatal ou privado responsável pelos graves crimes contra a humanidade. Quem responde perante o TPI é o próprio agente que comete o crime, e não o Estado de sua nacionalidade, ou onde o crime foi cometido.

Nesse quesito, a União Africana aparenta querer caminhar para incorporar uma jurisdição penal para condenar aqueles que cometem graves crimes contra a humanidade. No próprio website da Corte Africana consta a informação de que a UA encomendou um estudo à sua Comissão de Direitos Humanos sobre as implicações do alargamento da competência, para incluir a jurisdição penal e assim condenar a própria pessoa que comete graves crimes contra a humanidade. ${ }^{13}$

\footnotetext{
12 Sobre o tema, ver ainda a opinião de Naldi (2008), para quem as disposições das cláusulas clawback não impõem perigo de derrogação de direitos de forma descontrolada.

13 Informação disponível em: Cour africaine (2016).
} 


\section{Reflexões sobre a condenação de Habré para os sistemas regionais de direitos humanos}

A ressalva que se faz nesse caso do julgamento de Hissen Habré é que apesar da eficiência do tribunal, ele se configura como uma Corte ad hoc, criada exclusivamente para julgar o ditador, o que, em termos jurídicos, deveria ser evitado. Note-se que ele é julgado em outro país, em uma espécie de tribunal especial que conta com quase todos os juízes do Senegal, além da utilização da legislação de Senegal.

Por outro lado, o tribunal em três meses sentenciou o ditador, ouvindo 90 testemunhas que relataram as atrocidades cometidas, e o condenou à prisão perpétua. É um marco em termos de eficiência para um tribunal internacional, que recebeu o apoio das Nações Unidas. Esta inclusive considerou o acordo entre a União Africana e o Senegal como "um excelente exemplo de liderança regional e de vontade de lutar contra a impunidade para crimes internacionais." ${ }^{14}$

No entanto, o julgamento de Habré pode ter como pano de fundo um descontentamento dos países africanos com o Tribunal Penal Internacional. E por essa questão, a UA decidiu que o ditador do Chade deveria ser julgado em seu próprio continente. Essa desilusão para com o TPI pode ocorrer por três razões: seletividade do Tribunal; ingerência do Conselho de Segurança da ONU; e interferência de países com poder de veto do Conselho de Segurança que podem solicitar abertura de inquérito e impedir investigações, mas não podem ser julgados (PORTELLA JÚNIOR, 2016).

Uma primeira crítica que pode ser notada é a seletividade do TPI para com os países africanos. Observa-se que a maioria dos casos perante o TPI é de conflitos na África, enquanto conflitos da mesma magnitude, em países como Colômbia, Filipinas e Síria, ficam impunes.

Outra questão refere-se à interferência do Conselho de Segurança das Nações Unidas nos trabalhos do TPI. De acordo com os artigos 13 e 16 do Estatuto de Roma, que criou o Tribunal, o Conselho pode solicitar ao Procurador da Corte Penal a abertura de inquérito contra pessoas que cometeram crimes abarcados pela sua competência, além de poder interromper inquéritos e procedimentos criminais, ou impedir que prossigam, por meio de uma Resolução (SOMENZARI, 2005). Esse "poder" do Conselho pode levar à perseguição dos inimigos dos interesses geopolíticos dos seus membros e trazer impunidade para agentes de países aliados.

Ainda em relação ao Conselho de Segurança, note-se que os Estados Unidos, China e Rússia não são signatários do Estatuto e não podem ter seus nacionais julgados pelo TPI. No entanto, podem, via Conselho, solicitar a abertura de inquérito ou bloquear a tentativa de responsabilização de líderes de países aliados. Veja-se que em 2014, a França tentou aprovar uma Resolução no Conselho de Segurança para que o TPI investigasse os crimes derivados do conflito na Síria, mas a iniciativa foi

14 Informação disponível em Nações Unidas no Brasil (2016). 
vetada pela Rússia ${ }^{15}$ e pela China. ${ }^{16}$ E note-se que intervenções armadas dos Estados Unidos, como a invasão do Iraque e a anexação da Crimeia pela Rússia nunca entrarão na pauta do Tribunal.

Todas essas questões fizeram com que alguns países africanos já noticiassem sua intenção de retirar-se do Estatuto de Roma, a exemplo de África do Sul, Burundi e Gâmbia. Esse descontentamento foi sentido também na $28^{a}$ Conferência da União Africana, em fevereiro de 2017, quando foi aprovada uma Resolução (não unânime) da organização convocando os países a denunciarem o Estatuto de Roma e assim abandonar o TPI. ${ }^{17}$ Essa decisão não é vinculativa para os países, nem a UA é signatária do TPI, mas é um sintoma de que os países não estão contentes com o modo de atuação da Corte Penal Internacional. Frise-se também que a opinião negativa sobre o Tribunal não é unânime, havendo países a favor da continuidade do TPI (ainda que com reformas), mas os debates podem gerar ideias a legitimar novas propostas.

Uma delas, reforçada por Angola atualmente, é a criação de um novo tribunal no seio da União Africana, que teria também a competência criminal, semelhante ao TPI. Essa iniciativa já foi posta em marcha. Quando a União Africana foi criada, em 2003, foi adotado um Protocolo do Tribunal de Justiça da União Africana, que até hoje não entrou em vigor. Durante a $7^{a}$ Sessão Ordinária da Assembleia da UA, em julho de 2006, foi decidido fundir a Corte Africana de Direitos Humanos com o Tribunal de Justiça da União Africana, criando, assim, o Tribunal Africano de Justiça e Direitos Humanos (TAJDH). O Protocolo do Estatuto do TAJDH (Protocolo de Sharm El-Sheik) foi adoptado na $11^{\text {a }}$ Sessão Ordinária da Assembleia da UA no Egito, em 01 de julho de 2008. Esse protocolo prevê que a Corte Africana de Direitos Humanos continuará em funcionamento até um ano após a entrada em vigor do TAJDH (GARCIA, 2014).

O Protocolo de Sharm El-Sheik definia a criação de uma estrutura unificada, com jurisdição para decidir sobre todos os casos e disputas relativas à interpretação do Ato Constitutivo da União Africana, da Carta Africana dos Direitos Humanos e dos Povos, e protocolos adicionais.

Após tal fato, o Estatuto do TAJDH sofreu duas alterações principais. A primeira delas foi a introdução de uma nova seção criminal (Protocolo de Adis Abeba, 2012). O artigo $3^{\circ}$ do Estatuto com essa modificação assim dispõe: "O Tribunal é investido de uma jurisdição originária e de recurso, incluindo a jurisdição Penal internacional que será exercido em conformidade com as disposições do Estatuto anexo ao presente Protocolo." ${ }^{18}$

\footnotetext{
15 A Rússia havia assinado em 2000 o Estatuto de Roma, mas não o ratificou. Em 16 de novembro de 2016 o Presidente Putin decidiu retirar a assinatura anteriormente realizada, tendo na ocasião o Ministério das Relações Exteriores Russo emitido uma nota criticando a unilateralidade do TPI, declarando que em 14 anos de funcionamento o Tribunal havia ditado apenas quatro sentenças e consumido mais de um bilhão de dólares. Cfr. notícia em: RÚSSIA... (2016).

16 Para maiores informações em: Monge (2014).

17 Informação disponível em Melo e Santos (2017). Coincidentemente, nessa reunião o Ministro das Relações Exteriores do Chade, Moussa Faki Mahamat, foi eleito para exercer a presidência da Comissão da União Africana, o cargo executivo mais importante da organização.

18 Vide o Estatuto com essa alteração em African Uniuon (2012).
} 
No entanto, a esperança de que o Tribunal trouxesse uma inovação e luta contra a impunidade no continente africano acabou sendo minada parcialmente em 2014. Nesse ano foi adotada uma nova alteração ao Projeto do Estatuto do TAJDH, que ficou conhecido como Protocolo de Malabo. Nessa ocasião, os líderes africanos construíam uma estrutura penal com competências idênticas às do TPI, no entanto com a garantia de que não seria alvo da ação desse órgão jurisdicional, ou seja, criaram uma imunidade para si. O novo artigo 46 A bis do Protocolo de Malabo determina que não sejam iniciadas ou continuadas quaisquer acusações perante o Tribunal contra qualquer chefe de Estado ou de Governo da União Africana, ou qualquer pessoa que atue ou tenha o direito de atuar em seu nome ou outros funcionários do alto escalão do Estado com base em suas funções, durante o mandato (tradução nossa). ${ }^{19}$

Ante essa iniciativa, a Anistia Internacional elaborou um relatório sobre o Protocolo de Malabo no qual ressalta que essa questão é a mais polêmica do projeto. Afirma que a cláusula de imunidade trará sérias implicações na luta contra a impunidade pelos crimes internacionais na África e para a legitimidade e credibilidade do TAJDH. Em sua visão, a cláusula efetivamente impedirá a investigação e o julgamento dos Chefes de Estado e de Governo que usem sua posição ou autoridade para ordenar, planejar, financiar ou criar de outra forma crimes contra a humanidade, crimes de guerra ou atos de genocídio. Frise-se que a experiência já mostrou que, no continente africano, como em outros lugares, são aqueles que ocupam cargos de poder que normalmente abusam de sua autoridade e recursos estatais para cometerem crimes internacionais. Assim, a cláusula de imunidade essencialmente promove e fortalece a cultura da impunidade que já está entrincheirada na maioria dos países africanos. ${ }^{20}$

Além dessa crítica, Rodríguez (2017) ressalta que o Protocolo de Malabo não faz menção alguma sobre a relação com o Tribunal Penal Internacional, ou seja, se o novo tribunal africano seria uma jurisdição complementar, subsidiária ou de outra natureza. No entanto, o autor ressalta que como na União Africana a criação de instituições, a atribuição de competências e os processos de reforma não se caracterizam por sua celeridade, espera-se que com o tempo seja definida a relação com o TPI, assim como as demais críticas sejam levadas em consideração, para que não se percam os progressos já alcançados.

Até 15 de junho de 2017, o Protocolo original de criação do TAJDH contava com 30 assinaturas e seis ratificações. ${ }^{21}$ Por sua vez, o Protocolo de Malabo, que trouxe a imunidade para chefes de Estados, obteve nove assinaturas e nenhuma ratificação. ${ }^{22}$ Polêmicas à parte, o futuro desse

\footnotetext{
${ }_{19}$ Artigo no original em inglês: "No charges shall be commenced or continued before the Court against any serving African Union Head of State or Government, or anybody acting or entitled to act in such capacity, or other senior state officials based on their functions, during their tenure of office." Essa alteração ao Projeto do Estatuto do TAJDH original pode ser encontrada em um relatório feito pela Anistia Internacional específico sobre o Protocolo de Malabo, em língua inglesa (AMNESTY INTERNATIONAL, 2016).

20 Opinião da Anistia Internacional ao Protocolo de Malabo, disponível em um relatório criado em 2014 e intitulado Malabo Protocol: legal and institutional implications of the merged and expanded african court (AMNESTY INTERNATIONAL, 2016, p. 27).

21 Informação disponível em: African Union (2018).

22 Informação disponível em: African Union (2018).
} 
Tribunal que ainda não está em vigor é incerto, e há chances de que ele seja criado sem a cláusula de imunidade. Acaso ela seja incluída na proposta, será a perda de uma grande oportunidade da África de mostrar ao mundo que a luta contra crimes contra a humanidade deve ser severa para com aqueles que se utilizam do aparato estatal para cometer graves violações de direitos humanos.

O julgamento de Hissen Habré abre, assim, a porta para a inovação nos sistemas regionais de direitos humanos. Nem o sistema europeu nem o interamericano possuem competência para julgar agentes do estado ou pessoas físicas em razões de violações de direitos humanos. A responsabilidade para tais atos recai sobre o estado, que é condenado a reparar tais violações, e entre as medidas reparatórias encontra-se a de julgar e condenar os culpados.

Sem embargo, a prática dessas condenações em países subdesenvolvidos é complexa, principalmente quando se está lidando com estados onde há níveis de corrupção nos poderes responsáveis, uma prática de impunidade ou um aparato burocrático tão lento que inviabiliza qualquer ação contra os algozes. Nesse sentido, Zaverucha e Leite (2016) elaboraram um estudo no qual identificaram que entre as sentenças proferidas pela Corte Interamericana de Direitos Humanos entre 2001 e 2013 e que tiveram sua execução supervisionada pela Corte até 2015, em nenhum caso houve o cumprimento total da obrigação de investigar, julgar e sancionar os agentes estatais culpados de violações. Infelizmente os dados mostraram que a condenação, nesse tipo de reparação, surtiu um efeito mais simbólico do que efetivo.

Seja com a criação de um novo tribunal, seja incorporando uma competência penal na Corte Africana de Direitos Humanos, seja criando tribunais ad hoc para julgamento de casos específicos, a África mostrou com o julgamento de Hissen Habré que a impunidade para crimes contra a humanidade pode encontrar seu caminho no âmbito geográfico regional. $O$ continente africano, assim, cria uma nova modalidade de aparato jurídico internacional, da mesma forma que o Conselho da Europa inovou ao criar o Tribunal Europeu dos Direitos Humanos em 1950. A escolha mais racional, e à luz do direito internacional, é que seja um tribunal internacional permanente, com juízes independentes, procedimentos prévios, crimes previamente tipificados, penas expressamente dispostas e órgãos com poderes sancionatórios capazes de pressionar o cumprimento das decisões. No entanto, em um ambiente complexo e conturbado como o africano, a iniciativa das Câmaras Africanas Extraordinárias é um alerta para aqueles que se utilizam do Estado para cometer crimes contra a humanidade, assim como grupos terroristas e paramilitares que ocupam espaços deixados pelo Estado ou que tentam tomar o poder pela força.

Ao tratar da replicabilidade do modelo da CAE, Høgestøl (2016) defende que esse exemplo pode ser empregado em outras regiões. Explica que a combinação de elementos internacionais mínimos, envolvimento regional e fundamentação na jurisdição universal poderia fazer do modelo da CAE uma maneira eficiente de preencher as lacunas de impunidade deixadas pelo Tribunal Penal Internacional, além de ser um mecanismo de justiça regional alternativo que faria os julgamentos próximos do seu local de ocorrência (em um país vizinho, por exemplo). 
Assim, a combinação de mesclar um sistema de tribunais domésticos com alguns elementos internacionais e insights baseados na jurisdição universal poderia gerar um procedimento mais fácil, eficiente e econômico para um sistema regional de direitos humanos, como a ASEAN, a Liga dos Estados Árabes e o Sistema Interamericano da OEA, para processar graves violações de direitos humanos. Em situações nas quais o sistema judicial nacional não consegue julgar os crimes internacionais, um tribunal criado por um sistema regional de direitos humanos, dentro da estrutura de tribunais nacionais de outro país da região, tornaria o julgamento mais próximo das vítimas e daria aos órgãos regionais mais legitimidade sobre seus mecanismos de justiça internacional (HØGESTØL, 2016).

\section{0 caso Hissène Habré e a justiça de transição}

Desde 1990, quando Habré foi derrotado por Idriss Déby, inúmeros atores nacionais, regionais e internacionais estiveram envolvidos no caso para levá-lo à justiça para responsabilização criminal de seus atos. Habré ficou conhecido como o "Pinochet da África", em referência ao regime ditatorial imposto de August Pinochet, no Chile, entre 1973 e 1990, que também usou métodos de tortura e desaparecimento forçado de opositores ao seu regime. Estima-se que Habré seja responsável diretamente por 40 mil execuções e outras 200 mil torturas realizadas pela Diretoria de Documentação e Segurança (DDS) do Chade (HØGESTØL, 2016).

No Chade pós-ditadura, o novo governo criou uma Comissão da Verdade e Reconciliação para avaliar as extensões das violações a direitos humanos cometidas pelo ex-ditador. ${ }^{23} \mathrm{~A}$ iniciativa de promover uma Comissão da Verdade se ajusta à complexa dinâmica que impõe sobre uma nação promover a transição entre regimes díspares, como uma ditadura para uma democracia.

A Justiça de Transição, nesse aspecto, não deixa de ser um método de restabelecimento da reconciliação da sociedade, mas, também, de um instrumento que promova a responsabilização daqueles que violaram os direitos humanos de cidadãos. $O$ reconhecimento, pelo Estado, dessa violação é fundamental para o planejamento do futuro, numa perspectiva de educar para que tais violações jamais voltem a ocorrer.

A finalidade da justiça transicional implica o desencadeamento lógico de quatro esferas bem delimitadas: o direito à memória e à verdade; reparação das vítimas; processar os violadores dos direitos humanos; e, por fim, reformar as instituições. ${ }^{24}$

A primeira finalidade se refere à necessidade de se revelar a Verdade sobre os crimes cometidos por agentes da repressão do Estado em um determinado regime, possibilitando à nação a reconstrução de sua Memória histórica. $O$ direito à memória e à verdade se constitui como um dos elementos fundamentais para a recuperação de um espaço de experiência que deve ser reinterpretado sob a luz da liberdade, capaz de produzir novas narrativas que exteriorizem fatos que, por ventura,

$\begin{array}{ll}23 & \text { Para maiores detalhes ver: United States Institute of Peace (1990). } \\ 24 & \text { Essas características são defendidas por Van Zyl (2009), Seligmann-Silva (2009) e Santos (2009). }\end{array}$ 
tenham sido ocultados ou reorganizados diante dos interesses de um regime autoritário, mesmo frente a uma legislação que imponha políticas de esquecimento. Em linha extensiva, o direito à memória e à verdade contribui com premissas que:

[...] diz respeito ao direito presumido que cada cidadão possui de conhecer a verdade dos fatos que compõem a sua história (e do seu país); a segunda, por sua vez, consiste na ideia de que há de ser preservada a memória daquelas pessoas e/ ou grupos sociais que, no decorrer da história foram perseguidos e reprimidos (em alguns casos tão brutalmente que, como consequência, chegaram a ser mortos pelos agentes repressores do aparelho estatal), a fim de que, a partir da preservação de tais lembranças, situações semelhantes não mais ocorram. (GALLO, 2010, p. 138).

No caso do Chade, as ações da Comissão da Verdade e Reconciliação em conjunto com os grupos de vítimas do regime de Habré produziram inúmeros relatos que expuseram as faces da violência entre 1982 e 1990. Grande parte desse material compôs a denúncia processada pela Câmara Africana Extraordinária, que condenou o ex-ditador à prisão perpétua por crimes contra a humanidade.

Essas ações também auxiliam na forma como vítimas, Estado e sociedade civil se reorganizam para a composição do futuro pós-ditadura.

A segunda finalidade da justiça de transição consiste na reparação (em sentido amplo) das vítimas que tiveram seus direitos fundamentais violados. No caso Habré, os juízes da CAE trabalham para a fixação de um calendário de reparações às vítimas, que incluíram indenizações pecuniárias.

$\mathrm{Na}$ terceira etapa, a justiça de transição revela a imperiosa necessidade de se processarem judicialmente os perpetradores dos direitos humanos, ou seja, os agentes políticos responsáveis pelas violações sistemáticas de direitos (torturas, sequestros, homicídios, estupros, atentados violentos ao pudor, etc.). A punição de Habré torna-se um clássico exemplo de que a responsabilização pública e criminal de violadores de direitos humanos passa a ser uma realidade, um ponto de inflexão nas experiências de impunidade.

O caso de Habré não pode ser considerado um ato simbólico ou isolado, mas, sim, uma demonstração clara de que violações de tal natureza não têm encontrado guarida protetiva no ambiente político ou jurídico. A condenação, nas palavras do advogado das vítimas, Reed Brody, ${ }^{25}$ responsável pelas acusações nas CAE, é uma demonstração de que "um grupo determinado de sobreviventes, com tenacidade e perseverança, conseguiu justiça. É um exemplo para o mundo inteiro. E também um alerta para tiranos saberem que, se cometerem atrocidades, nunca estarão fora do alcance de suas vítimas." (JARDIM, 2016, p. 1).

Por fim, reformar as instituições perpetradoras de abuso, de modo que seja possível promoção da reconciliação, é uma das etapas finais da justiça de transição. Embora a situação do Chade, desde 1990, inspire ressalvas, até mesmo pela quantidade de conflitos internos, a decisão das CAE pode

${ }_{25}$ É advogado da Human Rights Watch, organização que acompanha as vítimas de Habré desde 2009. 
contribuir para o aperfeiçoamento de reformas amplas no sistema de proteção aos direitos humanos do governo do Chade, bem como influenciar outros Estados que compõem a União Africana.

\section{Conclusão}

O caso Hissène Habré abre um novo capítulo na justiça criminal internacional. Longe do Tribunal Penal Internacional, o ex-ditador do Chade foi julgado exemplarmente, em um prazo de três meses e com todos os direitos garantidos. Apesar de ter sido criado um tribunal ad hoc, a inovação advinda de um acordo da União Africana, responsável pelo Sistema Africano de Direitos Humanos, e o Senegal recebeu aplausos até do Alto Comissariado para os Direitos Humanos da ONU.

A inovação pelo fato de ser um tribunal ad hoc, assim como outras experiências do passado, como o Tribunal de Nuremberg, o Tribunal Penal para Ex-Iugoslávia e o Tribunal Penal para Ruanda, mostra que a busca pela luta contra a impunidade dos agentes políticos que cometem crimes contra a humanidade não é isenta de críticas. No entanto, assim como Nuremberg abriu um novo capítulo no direito internacional, gerando depois de um longo tempo o Tribunal Penal Internacional, o caso Hissène Habré pode ser a semente para a criação de um tribunal regional criminal, de caráter permanente, ainda inédito na história. E que se não for permanente, que os sistemas regionais de direitos humanos criem esse modelo ad hoc utilizado realizado pela CAE, enquanto amadurecem para uma Corte criminal permanente.

A seletividade de casos do TPI, que possui atualmente 10 casos em investigação, dos quais nove pertencem a países africanos, e a interferência de potências do Conselho de Segurança que não podem ser julgadas pelo tribunal, mas podem interceder nos trabalhos do TPI, fazem com que os países africanos se sintam incomodados com tal situação. E o caso Habré pode ser o combustível que faltava para o abandono da Corte Penal Internacional, para pôr em prática o projeto do TAJDH ou mesmo dotar a Corte Africana de Direitos Humanos de uma competência criminal. Mesmo assim, vislumbra-se que esse tipo de tribunal ad hoc pode existir ao lado do TPI, principalmente nos casos que fogem de sua jurisdição (por razões de o fato ter sido cometido antes de 2002, por exemplo). Essas questões da coexistência de Cortes criminais regionais e internacionais ainda merece um longo debate, de forma que a defesa restrita a uma ou outra opção ainda é cedo para ser feita.

Como a criação de um tribunal com esse aporte criminal não é simples, tendo-se que cuidar das estruturas físicas, garantir os aportes financeiros, apoio político dos países, treinamento de pessoal, criação de redes de contatos com autoridades nacionais e sistema de proteção de vítimas, entre outras questões, a experiência das Câmaras Africanas Extraordinárias mostrou-se válida. Foi um alerta para o continente de que a impunidade pode encontrar resistência quando há vontade política. E assim, espera-se que a União Africana aos poucos siga incentivando os países a assinarem e ratificarem a criação dessa justiça criminal regional, o que traria maior legitimidade para os julgamentos de crimes contra a humanidade no Continente. 
Ao lado dessas questões, o caso também pode ser interpretado sob a luz da justiça de transição. A punição aos perpetradores de direitos humanos é um dos elementos fundamentais para o processo de concretização ao direito à memória e à verdade, bem como abre caminho à construção coletiva para uma reconciliação nacional. Nos principais sistemas transicionais, poucos são os países que avançam na punição aos violadores de direitos humanos. O Brasil, por exemplo, insere-se nesse rol. ${ }^{26}$ Países como Chile e Argentina, no cone Sul, construíram um sistema em que muitos violadores foram responsabilizados. $\bigcirc$ Chade pode ser compreendido dentro de outras limitações se cotejado com essas experiências, mas, mesmo assim, constitui-se como uma referência de proteção regional, com impacto no presente e projeção de um futuro aberto e mais sensível aos direitos humanos.

\section{Referências}

AFRICAN UNION. List of countries which have signed, ratified/acceded to the protocol on the statute of the African Court of Justice and Human Rights. Addis Ababa, Ethiopia, 08 fev. 2018. Disponivel em: $<$ https://au.int/sites/default/files/treaties/7792-sl-protocol_on_the_statute_of_the_african_ court_of_justice_and_human_rights_3.pdf>. Acesso em: 10 ago. $20 \overline{17}$.

AFRICAN UNION. Relatório, instrumentos jurídicos e recomendações dos ministros da justiça/procuradores-gerais. Vigésima-Primeira Sessão Ordinária. Adis Abeba, Etiópia, 09-13 jul. 2012. Disponível em: <http://www.peaceau.org/uploads/ex-cl-731-xxi-p.pdf>. Acesso em: 10 ago. 2017.

ÁLVAREZ, Yuria Saavedra. El Sistema Africano de Derechos Humanos y de Los Pueblos. Prolegómenos. Anuario Mexicano de Derecho Internacional, Cidade do México, v. VIII, 2008, p. 671-712.

AMNESTY INTERNATIONAL. Africa: Malabo Protocol: Legal and Institutional Implications of the Merged and Expanded African Court. 22 Jan. 2016. Disponível em: <https://www.amnesty. org/en/documents/afr01/3063/2016/en/ > . Acesso em: 10 ago. 2017.

BICUDO, Hélio. Defesa dos direitos humanos: sistemas regionais. Estudos Avançados, v. 17, n. 47, p. 225-236, 2003.

CARVAJAL, Ilich Felipe Corredor. Analyse de la competence juridictionnelle a partir de la première decision de la Cour Africaine des Droits de l'Homme et des Peuples: l'affaire Hissène Habré. ACDI, Bogotá, v. 5, 2012.

CHAMBRE AFRICAINE EXTRAORDINAIRE D’ASSISES. Ministère Public c. Hissein Habré. Julgamento em 30 maio 2016. Disponível em: <http://forumchambresafricaines.org/docs/JugementCAEd'Assises_Penal\&Civil_.pdf >. Acesso em: 10 jun. 2017.

CHAMBRES AFRICAINES EXTRAORDINARIES. Ordonnance de non-lieu partiel, de mise en accusation et de renvoi devant la chambre africaine extraordinaire dt assises. 13 fev. 2015. Disponível em: <http://forumchambresafricaines.org/docs/OrdonnanceRenvoi_CAE_13022015.pdf >. Acesso em: 10 fev. 2017.

\footnotetext{
$\overline{26}$ Para maior referência, ver: Pereira (2017).
} 
CHAMBRES AFRICAINES EXTRAORDINAIRES. Textes de Base CAE. Disponível em: < http:// forumchambresafricaines.org/textes-de-base-cae>. Acesso em: 10 jun. 2017.

COUR AFRICAINE. Compétences de la cour. Disponível em: <http://fr.african-court.org/index. php/about-us/jurisdiction>. Acesso em: 29 set. 2016.

FREITAS, Jeane Silva; MACEDO, Sibelle Silva. Sistemas Regionais de Proteção aos Direitos Humanos: Relevância da Carta Africana dos Direitos do Homem e dos Povos. Revista Conjuntura Austral, v. 4, n. 18, p. 81-94, 2013.

GALLO, Carlos Artur. O direito à memória e à verdade no Brasil pós-ditadura civil-militar, Revista Brasileira de História \& Ciências Sociais, v. 2, n. 4, dez. 2010.

HØGESTØL, Sofie A. E. The Habré Judgment at the Extraordinary African Chambers: a singular victory in the Fight Against Impunity. Nordic Journal of Human Rights, v. 34, i. 3, p. 147-156, 2016.

GARCIA, Walker Marcolino dos Reis. O Sistema Africano de Protecção dos Direitos Humanos e a sua Garantia em Angola. Dissertação (Mestrado em Relações Internacionais e Estudos Europeus)Universidade de Évora, Évora, 2014. Disponível em: < https://dspace.uevora.pt/rdpc/bitstream/10174/11141/1/TESE\%20vers\%C3\%A3o\%20FInal\%2030\%20deAbril\%202014.pdf>. Acesso em: 10 ago. 2017.

HUMAN RIGHTS WATCH. Chad: the victms of HissèneHabré Still Awaiting Justice. Human Rights Watch, v. 17, i. 10 (A), jul. 2005.

JARDIM, Carolina. Condenação de Habré é um alerta para tiranos que cometem atrocidades, diz especialista. Jornal O Globo, 31 maio 2016. Coluna Mundo. Disponível em: < https://oglobo.globo. $\mathrm{com} / \mathrm{mundo} / \mathrm{condenacao-de-habre-um-alerta-para-tiranos-que-cometem-atrocidades-diz-especialis-}$ ta-19404513 >. Acesso em: 10 ago. 2017.

KUFUOR, Kofi Oteng. The African Human Rights System. Origin and Evolution. New York: Palvgrave, 2010.

MARKS, Stephen P. The Hissène Habré Case: The Law and Politics of Universal Jurisdiction. In: MACEDO, Stephen. Universal Jurisdiction: National Courts and the Prosecution of Serious Crimes Under International Law. Philadelphia: University of Pennsylvania Press, 2004.

MELO, Marta; SANTOS, Nélio dos. Cabo Verde contra abandono coletivo do TPI, Angola defende tribunal africano. DW, 01 fev. 2017. Disponível: <http://www.dw.com/pt-002/cabo-verde-contra-abandono-coletivo-do-tpi-angola-defende-tribunal-africano/a-37374975>. Acesso em: 10 ago. 2017.

MONGE, Yolanda. A Rússia e a China impedem que tribunal da ONU investigue os crimes na Síria. El País, 14 maio 2014. Disponível em: <https://brasil.elpais.com/brasil/2014/05/22/internacional/1400781900_687551.html>. Acesso: 10 ago 2017.

MUNIÁIN, Laura San Martín Sánchez De.Comentarios Acerca de La Creación de Un Tribunal Africano de Derechos Humanos Y de Los Pueblos. REV - Anuario Español de Derecho Internacional, v. XV, p. 505-528, 1999. 
NAÇÕES UNIDAS NO BRASIL. Chefe de direitos humanos da ONU elogia sentença de ex-presidente Chadiano Hissène Habré. ONUBR, 04 jul. 2016. Disponível em: < https://nacoesunidas.org/ chefe-de-direitos-humanos-da-onu-elogia-sentenca-de-ex-presidente-chadiano-hissene-habre/ > . Acesso em: 29 set. 2016.

NALDI, Gino. The African Union and the Regional Human. In: EVANS, Malcom D.; MURRAY, Rachel (Ed.). The African Charter On Human And Peoples' Rights. The System in Practice 1986-2006. New York: Cambridge Universitary Press, 2008. p. 20-48.

NAVARRO, Marta Sosa. La evolución de la obligación de extraditar o juzgar a través del caso Hissène Habré. Revista Electrónica de Estudios Internacionales, Madrid, n. 26, dic. 2013.

PEREIRA, Maria Cristina Cardoso. Conselho Federal da Ordem dos Advogados do Brasil: apoio à ditadura, interesses da categoria e interpretações da democracia entre os anos 1964-1965. Revista Jurídica da UFERSA, Mossoró, v. 1, n. 1, 2017.

PIOVESAN, Flávia. Direitos Humanos e Justiça Internacional: um estudo comparativo dos sistemas regionais europeu, interamericano e africano. 5. ed. São Paulo: Saraiva, 2014.

PIRES, Maria José Morais. Carta Africana Dos Direitos Humanos e dos Povos. Documentação e Direito Comparado, n. 79/80, p. 333-350, 1999.

POlYMENOPOUlOU, Eleni. African Court On Human And Peoples' Rights, African Commission On Human And Peoples' Rights V Great Socialist People's Libyan Arab Jamahiriya, Order For Provisional Measures 25 March 2011. International and Comparative Law Quarterly, v. 61, i. 3, p. 767-775, 2012.

PORTELLA JÚNIOR, José Carlos. O futuro incerto da justiça penal internacional. Portal Canal Ciências Criminais, 27 out. 2016. Disponível em: <https://canalcienciascriminais.com.br/futuro-incerto/>. Acesso em: 10 ago. 2017.

RKIOUA, Abdelhamid Adnane. Los Derechos Sociales En La Carta Africana De Los Derechos Humanos Y De Los Pueblos. Lex social - Revista de los Derechos Sociales, n. 1, p. 31-54, enero/jun. 2012.

RODRÍGUEZ, Juan Bautista Cartes. El Tribunal Africano de Derechos Humanos y de los Pueblos: ¿̀hacia un África en paz?. Anuario Mexicano de Derecho Internacional, v. XVII, p. 251-289, 2017.

SANTOS, Cecília MacDowell. A justiça ao serviço da memória: mobilização jurídica transnacional, direitos humanos e memória da ditadura. In: SANTOS, Cecília MacDowell et al. (Org.). Desarquivando a ditadura - memória e justiça no Brasil. São Paulo: Hucitec, 2009. v. II.

SELIGMANN-SILVA, Márcio. Anistia e (in)justiça no Brasil: o dever de justiça e a impunidade. In: SANTOS, Cecília MacDowell et al. (Org.). Desarquivando a ditadura - memória e justiça no Brasil. São Paulo: Hucitec, 2009. v. II.

SOLER, Salvador Garrido. El Papel de la Historia en La Fundamentación de los Derechos Humanos: Las Cartas de Mandén Y Kurukan Fuga y Su Posición En El Sistema Africano De Protección De Los Derechos Humanos. Universitas. Revista de Filosofía, Derecho y Política, n. 16, p. 127-156, jul. 2012.

SOMENZARI, Isteissi Aires Garcia. O papel do Conselho de Segurança da ONU no Tribunal Penal Internacional. Revista Brasileira de Direito Internacional, v. 1, n. 1, p. 202-224, jan./jun. 2005. 
TAFFO, Frédéric Foka. The Hissène Habré Case. African Centre for the Constructive Resolution of Disputes. ACCORD Org, 23 dec. 2015. Disponível em: <www.accord.org.za/conflict-trends/the-hissene-habre-case/>. Acesso em: 05 mar. 2016.

UNITED STATES INSTITUTE OF PEACE. Truth Commission: Chad. 29 set. 1990. Disponível em: <https://www.usip.org/publications/1990/12/truth-commission-chad>. Acesso em: 10 jun. 2017.

VAN ZYL, Paul. Promovendo a justiça transicional em sociedades pós-conflito. Revista Anistia Política e Justiça de Transição, Brasília: Ministério da Justiça, n. 1 jan./jun. 2009.

ZAVERUCHA, Jorge; LEITE, Rodrigo. A Impunidade de Agentes Estatais nos Casos Julgados pela Corte Interamericana de Direitos Humanos. Revista Brasileira de Segurança Pública, v. 10, n. 1, p. 88-107, 2016.

Data da submissão: 03 de novembro de 2017 Aceito em: 04 de maio de 2018 
